\title{
Frail old people at the margins of care: some recent research findings ${ }^{\dagger}$
}

\author{
DAVID CHALLIS and JANE HUGHES
}

\section{Background Community-based care at the margin is a substitute for institutional care. Three factors are considered critical: definitions of eligibility, assessment procedures and balance of care.}

Aims To examine determinants of the margin between institutional and homebased care, review current practice, identify the implications and contribute to planning of integrated long-term care services.

Method A selective review was made of findings from research conducted after the community care reforms.

\section{Results Marked variability and}

inconsistency in eligibility and assessment processes may contribute to misplacement of frail older people. There remains capacity to shift the balance of care from institutional to home-based care within reasonable cost parameters, particularly with more integrated services.

\section{Conclusions Greater standardisation} of approaches to the determination of eligibility for social care and to assessment of need is required. Providing care at home for some of those currently entering care homes is feasible, but will require different service structures and staff roles, including specialist clinicians.

\section{Declaration of interest None.}

In the development of community-based care for old people, three interlinked strands of service development have been noted. These are the move away from institutional provision; the strengthening of home-based care; and the introduction of care management (Challis, 1992). Developments in nursing and residential care for old people must be set in this context and that of current Government policy initiatives to modernise health and social service provision for adults (Department of Health, 1998a, 2000). Key themes include fair access to care; enhancement of independence and care at home; and consistency in service provision. This paper examines these in the light of recent research by the Personal Social Services Research Unit (PSSRU) at Manchester into arrangements for the long-term care of older people relevant to access, assessment and balance of care. Each of these can critically influence the margin between community-based and institution-based care in any service system.

\section{Key components of community-based care}

There has been a long-term commitment to the development and extension of community-based care in the UK. A particularly significant factor influencing this process was the increase in the number of private nursing and residential care homes which developed as a result of funding for such placements being available through the Department of Social Security during the 1980s. Indeed, a key objective of the community care reforms was to remove the built-in bias towards residential and nursing-home care (Department of Health, 1998a). As part of this process individual social services departments were required to develop eligibility criteria to assist in the targeting of services on those in greatest need. These were significant in defining access to long-term care and other services, together with their key objective of improved assessment of need. It was envisaged that social services departments would accomplish the latter in conjunction with medical, nursing and other interests. More recently the importance attached to rehabilitation and intermediate care in continuing care establishments has demonstrated the significance of assessment subsequent to placement. To ensure the targeting of packages of care for an older person in response to assessed need, resources must be available. To achieve this requires social services departments to develop a spectrum of services appropriate to the needs of their population, another of the objectives of the community care legislation. Crucial in this context is the balance between community and institution-based care and mechanisms to promote more appropriate use of resources.

\section{METHOD}

Evidence is drawn from three studies that address eligibility, assessment and balance of care.

\section{Summary of methodologies}

\section{Eligibility criteria study}

Documents were supplied by 83 social services departments in England, three of which submitted incomplete data:

(a) codification was developed using presence or absence of nine key domains: within each domain presence of specific detail; and whether eligibility was service-specific or more general;

(b) analysis and development of quality indicators.

\section{Assessment study}

Fifty comprehensive assessment documents for social care in the UK were analysed:

(a) contents analysis for presence or absence of 33 core domains;

(b) analysis of degree of detail, structure and standardisation.

\section{Balance-of-care study}

Retrospective data collection representing 330 admissions to residential or nursing homes in one social services department:

(a) comparison with national data on admissions; 
(b) categorisation of admissions into 16 types and representative cases randomly selected within each category;

(c) simulation exercise with 16 staff estimating care packages for representative cases of patients previously placed in long-term care;

(d) projection of the simulation results to estimate the cost of alternative care arrangements.

\section{RESULTS}

\section{Access to long-term care}

After the implementation of the community care reforms it was noted that eligibility criteria were not always being consistently interpreted and applied or linked to the allocation of resources (Department of Health, 1998a). Four years after the introduction of the community care legislation a study of eligibility criteria for services for old people was undertaken (Hughes $e t$ al, 1997). All social services departments in England were asked to supply details of these and a response rate of $71 \% \quad(83$ departments) was achieved; 80 respondents provided complete data. In terms of exploring how social services departments conceptualise and respond to the needs of old people in order to determine the most appropriate form of care for them, two of the research findings are of particular interest: the content and the type of eligibility criteria.

First, regarding content, nine domains of potential need were identified: physical health, mental health, activities of daily living, instrumental activities of daily living, the role of informal carers, risks, finance, housing and the existence of support networks in the community; and the extent of their inclusion in eligibility criteria was examined. The first six of these domains were seen as particularly significant in determining eligibility for assessment and service provision. However, they were included in the documentation of only $64 \%$ (51) of the departments, reflecting both the paucity and variability of the criteria used to make important judgements about arrangements for long-term care of old people.

Second, the extent to which social services departments had separate criteria to determine eligibility for residential and nursing care on the one hand and homebased care on the other was explored. The

Table I Mental health components in the social care eligibility criteria of social services departments

\begin{tabular}{lccc}
\hline Domain & $\begin{array}{c}\text { All departments } \\
(n=80)^{\prime} n(\%)\end{array}$ & $\begin{array}{c}\text { Departments with } \\
\text { combined eligibility criteria } \\
(n=5 I) n(\%)\end{array}$ & $\begin{array}{c}\text { Departments with } \\
\text { separate eligibility criteria } \\
(n=29) n(\%)\end{array}$ \\
\hline Cognitive impairment & $34(43)$ & $15(29)$ & $19(66)$ \\
Depression & $18(23)$ & $8(16)$ & $10(34)$ \\
Disturbed behaviour & $45(56)$ & $23(45)$ & $22(76)$ \\
Supervision/support required & $36(45)$ & $19(37)$ & $17(57)$ \\
\hline
\end{tabular}

I. Data were missing for three of the 83 respondents.

majority $(64 \% ; 51)$ had a single set of criteria for both modes of care. However, separate criteria for the two forms of care may be indicative of a more targeted approach to the allocation of scarce resources, since this permits greater specificity of criteria for access to services. This is clearly evident in the domain relating to mental health. Table 1 demonstrates that not all respondents included key indicators of mental state in their eligibility criteria. Disturbed behaviour was noted by $56 \%$ of the departments but the other three indicators were cited by less than half. Of particular interest is the finding related to depression. Thirty-four per cent of the departments with separate criteria included depression compared with $16 \%$ of those with combined criteria. A similar, albeit less marked, distribution is evident in respect of cognitive impairment. The inclusion of these indicators is crucial in ensuring access to services for older people with mental health needs and, as Table 1 demonstrates, these features are more likely to be present when social services departments have devised separate criteria for residential and domiciliary care.

\section{Assessment - the identification of need}

Following the implementation of the community care reforms a number of small-scale studies and inspections by the Department of Health raised questions about the quality, reliability and validity of assessment procedures employed in social care. These are summarised by Challis (1999). More recently, a national study of care management arrangements, which achieved an $84 \%$ response rate, found that generic assessment documents were still in use in more than half $(61 \%)$ of social services departments, a similar picture to that previously criticised by the
Department of Health in 1993. Specialist documentation was least likely to be found for older people and most likely for adults with mental health problems under the age of 65 years (Challis et al, 1998a).

A second study examined in detail assessment approaches for old people receiving social care. Documents described as 'comprehensive' or 'complex' were collected from a sample of social services departments, social work departments, and health and social services boards in the UK in 1995, 2 years after the introduction of the community care legislation. An analysis of the contents of assessment documents was undertaken (Stewart et al, 1999). Each document was evaluated by the extent to which 33 key domains were covered, recorded in a structured fashion, recorded in detail, and whether standardised indicators were employed. Table 2 compares the domains of activities of daily living (ADL) and mental health. It shows that documentation demonstrated considerable variation in different domains. Although the levels of coverage of ADL and mental health domains were similar, the levels of structure varied considerably, with ADL being more structured. The degree of detail recorded showed even greater variation. For example, while cognition and depression were noted in over four-fifths of assessments, they were detailed only rarely (in $18 \%$ and $6 \%$ respectively). In contrast, ADL information was detailed in nearly half of assessment documents. This is of particular concern in view of the high incidence of depression in social services home care populations and the potential for this to be amenable to appropriate treatment (Bannerjee et al, 1996). Finally, whereas $14 \%$ of assessment documents would permit approximation to standardised measures of ADL (Katz \& Akpom, 1976), in none of them was information about depression or cognitive impairment 
Table 2 Prevalence (\%) of social care assessment content in documents from 50 health and social services offices

\begin{tabular}{lcccc}
\hline Domain & Coverage & Structured approach & Detailed & Standardised \\
\hline Activities of daily living & & & & \\
Feed & 84 & 52 & 44 & 14 \\
Bathe & 92 & 58 & 46 & 14 \\
Transfer & 88 & 56 & 48 & 14 \\
Toilet & 88 & 56 & 46 & 14 \\
Dress & 94 & 60 & 46 & 14 \\
Mobility & 94 & 56 & 46 & - \\
Mental health & & & 18 & - \\
Cognition & 90 & 42 & 6 & - \\
Depression & 88 & 30 & 6 & - \\
Behaviour patterns & 58 & 22 & & \\
\hline
\end{tabular}

Data from Stewart et al, 1999.

similarly recorded. In many ways the lack of structure, detail and standardisation is surprising, since there are brief, wellvalidated indicators of cognitive impairment and depression which could have provided guidance. It was concluded that professionally relevant standardisation would be a desirable trend for the future development of assessment schedules, given the variety of different staff with different training and professional socialisation experiences who would be expected to undertake the assessment of need. This is particularly relevant to the National Service Framework for Older People (Department of Health, 2001).

Since the introduction of care management, concern about the lack of appropriate health care input to social care assessments of need has been constant (Challis, 1999). Stewart et al (1999), in their analysis of assessment documentation, noted that only $24 \%$ of the assessment forms were used jointly by health and social services. It was also noted that while a number of assessment forms prompted for specialist assessment to be undertaken by health staff, the extent to which this occurred in practice was unclear. A national study of care management arrangements for all user groups has confirmed these findings. For example, in respect of older people with dementia, $24 \%$ of social services departments reported a common set of assessment documents shared with at least one of the trusts with which they worked, for both care management and the Care Programme Approach (Hughes et al, 2001). In respect of all user groups it was reported that health professionals coordinated assessments in about a quarter of authorities (Challis et al, 1998a).

Although the majority of social services departments have established time limits for the conducting of reviews of old people admitted to residential and nursing-home care, these guidelines were not being adhered to. Moreover, there was a lack of clarity about the purpose of reviews and their content (Department of Health, 1998b). Indeed, there is scant evidence of the existence or impact of assessment of need after entry to long-term care, despite a number of studies that have identified the range and pattern of needs of nursing-home and residential care populations (Challis et al, 2000a; Godlove Mozley et al, 2000). In the USA the need for more adequate resident assessment in long-term care resulted in the development of a uniform resident assessment system: the Minimum Data Set Resident Assessment Instrument (MDS/RAI). It has two components, the Minimum Data Set (MDS) and the Resident Assessment Protocols (RAPs), guidelines for the evaluation of potential problems. A UK version is now available (Challis et al, 2000b).

\section{Balance of care}

On both a national and an international basis there are marked variations in the balance of resources invested in residential and nursing-home care on the one hand and community care on the other (Challis, 1996). Few social services departments have systematically addressed this issue in the UK and, in contrast to other countries, no government guidance has been issued.
Recent work in one social services department involved collection of data on a cohort of 330 patients admitted to longterm care from both the community and hospital (Challis et al, 2000c). Both practitioners and managers were involved in a simulation exercise to estimate the cost of community care packages for people who had been placed in long-term care. In addition to financial projections based on estimates of the number of residents who could be diverted from long-term care, the research identified key areas for service development arising from suboptimal placement decisions. Sixteen staff worked in four groups. Using standard case summaries, each group had to reach a consensus on the care package deemed appropriate to support a particular representative individual at home. The resultant proposals were then evaluated by the management panel, which authorised high-cost care packages on an 'as if real' basis.

The 330 patients represented 232 entrants to long-term care, comprising consecutive admissions from the community and a $50 \%$ sample of those from hospital over a 9-month period. Following categorisation of these into 16 types, 197 cases were included ( $60 \%$ of all admissions). Following the evaluation by practitioners and the management panel, cases representing 70 individuals were seen as suitable for community-based care within existing service parameters: $21 \%$ of the overall group and $36 \%$ of those categorised into the 16 case types. Over $60 \%$ of those for whom care at home was identified as a feasible alternative to placement in a residential or nursing home were not among the most frail and vulnerable old people receiving assistance from the social services department, and therefore were probably least appropriately placed. They were characterised by low levels of both dependency (Mahoney \& Barthel, 1965) and cognitive impairment (Morris et al, 1994), and were supported at home by an informal carer. On discharge from hospital they had been admitted to long-term residential care. It is not unreasonable to infer that if a specialist hospital discharge service with clear eligibility criteria and adequate assessment processes had existed, a substantial proportion could have returned home rather than entering a residential home. They would certainly be suitable candidates for an intermediate care service (Department of Health, 2000).

Additionally, a comparison was made between a group of old people admitted 
Table 3 Comparison of characteristics of patients admitted from the community to long-term care or supported by the intensive domiciliary care service in one social services department

\begin{tabular}{|c|c|c|c|c|}
\hline & \multicolumn{4}{|c|}{ Case type } \\
\hline & \multicolumn{2}{|c|}{$\begin{array}{c}\text { Community admissions to } \\
\text { long-term care }\end{array}$} & \multicolumn{2}{|c|}{$\begin{array}{c}\text { Intensive care } \\
\text { management service }\end{array}$} \\
\hline & $n$ & $\%$ & $n$ & $\%$ \\
\hline \multicolumn{5}{|l|}{ Cognitive status ${ }^{\prime}$} \\
\hline Intact or mild impairment (MDS CPS 0-3) & 72 & 80 & 20 & 62 \\
\hline Severe impairment (MDS 4-6) & 18 & 20 & 12 & 38 \\
\hline Total & 90 & 100 & 32 & 100 \\
\hline \multicolumn{5}{|l|}{ Dependency ${ }^{2}$} \\
\hline High dependence (Barthel 0-8) & 16 & 18 & 19 & 59 \\
\hline Moderate dependence (Barthel 9-II) & 22 & 24 & 7 & 22 \\
\hline Low dependence (Barthel I2+) & 52 & 58 & 6 & 19 \\
\hline Total & 90 & 100 & 32 & 100 \\
\hline \multicolumn{5}{|l|}{ Chi-squared test: } \\
\hline \multicolumn{5}{|l|}{ Cognitive impairment: $\chi^{2}=3.89, P<0.05$} \\
\hline Dependency: $\chi^{2}=20.24, P<0.001$ & & & & \\
\hline
\end{tabular}

I. Cognitive status assessed using the Minimum Data Set Cognitive Performance Scale (MDS CPS; Morris et al, 1994). 2. Dependency assessed using the Barthel Index (Mahoney \& Barthel, 1965).

to residential and nursing-home care from the community and a group of old people who were at that time supported at home by an intensive care management service (Challis et al, 1990) in the same area (Table 3). A greater proportion of those with severe cognitive impairment received assistance at home from the intensive care management service compared with those who entered long-term care from the community $(P<0.05)$. In addition, more of those receiving intensive care management had high levels of physical dependency compared with those admitted to long-term care from the community $(P<0.001)$. This indicates the capacity of intensive care management as a means of supporting frail and vulnerable old people in their own homes. However, more recent research shows that few social services departments have an intensive care management service focusing exclusively on older people with high needs or at high levels of risk (Challis et al, 2001).

\section{DISCUSSION}

\section{Key findings}

Three findings of particular significance emerge. First, there is marked variability within the processes for managing access to social care services, whether community or residential and nursing-home care. Second, shortfalls and lack of consistency are evident in the assessment of need both prior to and after admission to long-term care. Third, there is considerable scope for more systematic exploration of the appropriate balance of care in any defined geographical area.

\section{Integrated approaches: lessons from overseas}

Is it possible to achieve a more integrated pattern of service provision better suited to individual need? From the Aged Care reforms in Australia there is some evidence that it is possible to identify mechanisms to address these issues of eligibility, assessment and balance of care. Four factors can be identified in these reforms: the enhancement of content and scope of community services; more coordinated and intensive care at home; greater standardisation and multi-disciplinarity of assessments; and linking reimbursement for continuing care to resident dependency. These appear to have influenced patterns of admission and dependency levels of those admitted to residential and nursing homes (Department of Health, Housing and Community Services, 1992).

\section{Towards greater integration: developments in England}

In England there are signs of similar developments. Central government has advocated the importance of intensive care management (Department of Health, 1997). There have also been a number of policy initiatives that have encouraged social services departments to develop joint community-based services with the National Health Service to avoid inappropriate admission to hospital and facilitate return home (Department of Health, 1998a,b, 2000). More tentatively, Cm 4169 (Department of Health, 1998a) has advocated greater standardisation of eligibility and assessment, and further guidance is awaited through the implementation of the National Service Framework for Older People, in which a single assessment process is specified.

\section{Role of specialist clinicians}

The contribution of the specialist clinician to community-based care is likely to be of increasing importance. The Australian Aged Care reforms suggest that the contribution of members of a multi-disciplinary team may be the key to determining more appropriate entry to long-term care. They also demonstrate the potential gain of linking specialist secondary health care resources such as geriatric medicine and old age psychiatry with community care, particularly care management (Challis et al, 1998b). The extent to which such developments are facilitated by the Government's modernisation agenda, including care trusts and partnership arrangements, for the care of vulnerable old people has yet to be determined.

\section{REFERENCES}

Bannerjee, S., Shamash, K., Macdonald, A., et al (1996) Randomised controlled trial of effect of intervention by psychogeriatric team on depression in frail elderly people at home. BMJ, $\mathbf{3} \mathbf{3}$, |058-|06|.

Challis, D. (1992) Community care of elderly people: bringing together scarcity and choice, needs and costs. Financial Accountability and Management, 8, 77-95.

- (1996) Community care. In Epidemiology in Old Age (eds S. Ebrahim \& A. Kalache), pp. 126-135. London: BMJ Publications.

- (1999) Assessment and care management: developments since the community care reforms. In With Respect to Old Age (eds M. Henwood \& G. Wistow), pp. 69-86. Research Volume 3, Cm 4192-II/3. London: Stationery Office. 
_, Chessum, R., Chesterman, J., et al (1990) Case Management in Social and Health Care: The Gateshead Community Care Scheme. Canterbury: Personal Social Services Research Unit, University of Kent.

\section{_ , Darton, R., Hughes, J., et al (1998a) Care} Management Study: Report on National Data. Mapping and Evaluation of Care Management Arrangements for Older People and Those with Mental Health Problems. Cl(98) I5. London: Department of Health.

_, _ \& Stewart, K. (1998b) Community Care,

Secondary Health Care and Care Management.

Aldershot: Ashgate.

_ , Godlove Mozley, C., Sutcliffe, C., et al (2000a) Dependency in older people recently admitted to care homes. Age and Ageing, 29, 255-260.

—, Stewart, K., Sturdy, D., et al (2000b) UK Long Term Care Resident Assessment Instrument: Users' Manual. York: InterRAI UK.

_ , McNiven, F., Hughes, J., et al (2000c) Estimating the Balance of Care. Discussion Paper M021/1677. Manchester: PSSRU, University of Manchester.

_, Darton, R., Hughes, J., et al (200I) Intensive care management at home: an alternative to institutional care. Age and Ageing, 30, 409-413.

Department of Health (1997) Better Management, Better Care. The Sixth Annual Report of the Chief Inspector, Social Services Inspectorate 1996/97. London: Stationery Office.

- (1998a) Modernising Social Services. Promoting Independence, Improving Protection, Raising Standards (Cm 4169). London: Stationery Office.

- (1998b) Care Management Study: Care Management Arrangements. $\mathrm{Cl}(98)$ 15. London: Department of Health.

(2000) The NHS Plan: A Plan for Investment, A Plan for Reform. London: Stationery Office.

- (200I) National Service Framework for Older People. London: Department of Health.

Department of Health, Housing and Community Services (1992) It's Your Choice: National Evaluation of Community Options Projects. Canberra: Australian Government Publishing Service.

Godlove Mozley, C., Challis, D., Sutcliffe, C., et a (2000) Psychiatric symptomatology in elderly people admitted to nursing and residential homes. Ageing and Mental Health, 4, 136-141.

\section{CLINICAL IMPLICATIONS}

More standardised approaches to assessment of frail old people are needed to contribute to greater equity and appropriateness of care.

- Extension of intensive home support services is likely to be required to provide real home-based alternatives to residential and nursing-home care.

- An emerging role for specialist clinicians may be to contribute to long-term care decisions.

\section{LIMITATIONS}

Analysis of documentation does not take into account application in practice.

- Inter- and intra-authority variation in documentation is not sufficiently captured, thereby underestimating the degree of inconsistency.

- Further evidence of the extent of national variation in capacity to move the balance of care is required.

DAVID CHALLIS, PhD, JANE HUGHES, MSc, Personal Social Services Research Unit, Faculty of Medicine, Dentistry, Nursing and Pharmacy, University of Manchester, UK

Correspondence: Professor David Challis, PSSRU, Dover Street Building, University of Manchester Oxford Road, Manchester MI3 9PL, UK

(First received 28 July 2000, final revision 8 May 200I, accepted 23 May 200I)

Hughes, J., Challis, D., Gill, J., et al (1997) The eligibility lottery. Working with Older People, I, $14-16$

_ , Stewart, K., Challis, D., et al (200I) Care management and the care programme approach: towards integration in old age mental health services. International Journal of Geriatric Psychiatry, 16 $266-272$

Katz, S. \& Akpom, C. A. (1976) A measure of primary sociobiological functions. International Journal of Health Services, 6, 493-508.
Mahoney, F. I. \& Barthel, D. W. (1965) Functional evaluation: the Barthel Index. Maryland State Medical Journal, 14, 61-65.

Morris, J., Fries, B., Mehr, D., et al (1994) MDS Cognitive Performance Scale. Journal of Gerontology, 49 $174-182$.

Stewart, K., Challis, D., Carpenter, I., et al (1999) Assessment approaches for older people receiving social care: content and coverage. International journal of Geriatric Psychiatry, 14, 147-156. 